Total $\mathbf{n}$ LTB

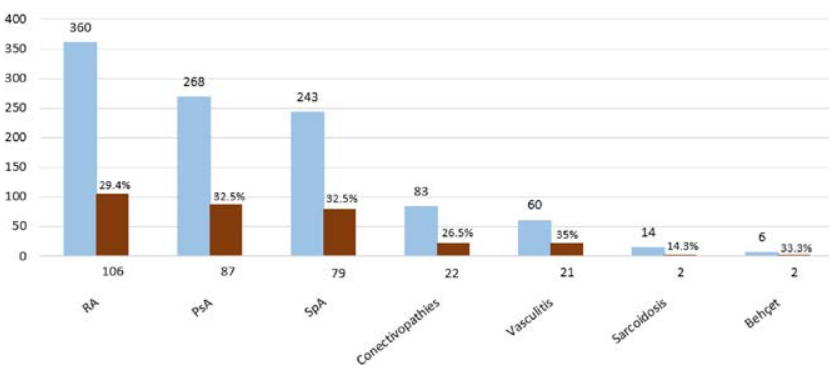

Figure 1. Prevalence of LTBI in different underlying R-IMID

LTBI: Latent tuberculosis infection, PsA: Psoriatic arthritis, RA: Rheumatoid arthritis, SpA: Axial spondyloarthritis.

Diagnosis of LTBI: Positive TST(+booster) and/or IGRA test.

Disclosure of Interests: David Martínez-López: None declared, Joy Osorio-Chavez: None declared, Carmen Álvarez-Reguera: None declared, Virginia Portilla: None declared, Miguel A González-Gay Speakers bureau: Abbvie, Pfizer, Roche, Sanofi and MSD, Consultant of: Abbvie, Pfizer, Roche, Sanofi and MSD, Grant/research support from: Abbvie, MSD, Jansen and Roche, Ricardo Blanco Speakers bureau: Abbvie, Pfizer, Roche, Bristol-Myers, Janssen, Lilly and MSD, Consultant of: Abbvie, Pfizer, Roche, Bristol-Myers, Janssen, Lilly and MSD, Grant/research support from: Abbvie, MSD, and Roche DOI: 10.1136/annrheumdis-2021-eular.2900

\section{POS1437 LATENT TUBERCULOSIS INFECTION IN RHEUMATIC DISEASES: A REAL-LIFE STUDY OF THREE APULIAN CENTRES. DATA FROM BIOPURE REGISTRY}

M. Fornaro ${ }^{1}$, D. Goletti ${ }^{2}$, A. Abbruzzese ${ }^{1}$, M. G. Anelli ${ }^{1}$, A. Semeraro ${ }^{3}$, N. Maruotti ${ }^{4}$, F. P. Cantatore ${ }^{4}$, F. Cacciapaglia ${ }^{1}$, F. lannone ${ }^{1}$ on behalf of BIOlogic aPUlian REgistry (BIOPURE). ${ }^{1}$ Rheumatology Unit, Department of Emergence and Transplantation (DETO), University of Bari, Bari, Italy; ${ }^{2}$ Translational Research Unit, Department of Epidemiology and Preclinical Research, National Institute for Infectious Diseases, L. Spallanzani, Roma, Italy; ${ }^{3}$ Rheumatology Unit, ASL Taranto, Taranto, Italy; ${ }^{4}$ UOC Reumatologia Universitaria, University of Foggia, Foggia, Italy

Background: Latent tuberculous infection (LTBI) is very common in the world and screening for it is essential before starting treatment with biotechnological drugs

Objectives: The aims of our study were to assess the prevalence in Apulia of LTBI among patients affected with rheumatic disease and to record the cases of tuberculosis (TB) infection among patients treated with biologic agents.

Methods: We analysed data of patients included in BIOPURE registry from 2008 to 2018, who underwent Quantiferon (QTF) test as routinely screening for biologic treatment. Demographic and clinical data were recorded at the time of the first QTF assessment and this time point was considered the "baseline" of the study. Data regarding further QTF tests performed during follow-up was also acquired by electronic charts. Prophylaxis administration and bDMARD treatments were recorded for patients with positive QTF test. All tuberculosis infections were recorded during the entire time of follow-up.

Results: Three thousand thirty-five patients (female $67.2 \%$, mean age $52 \pm 18.3$ years) were included in these study, 2692 patients $(88.7 \%)$ had inflammatory arthritis $(28.2 \%$ rheumatoid arthritis, $33 \%$ psoriatic arthritis and $27.4 \%$ spondyloarthritis), 129 (4.2\%) patients had connective tissue disease, whereas 214 $(7.1 \%)$ patients were affected by others rheumatic diseases. The prevalence of LTBI was 10.7\% (326 patients) at baseline. Comparisons between positive and negative patients for QTF are reported in Table 1. We acquired data of LTBI prophylaxis of 284 patients; 235 out 265 patients treated with isoniazid completed the treatment, whereas 19 out 19 patients treated with rifampicin completed the prophylaxis regimen. The main cause of isoniazid withdrawal was hypertransaminasemia, but 8 patients then completed prophylaxis with rifampicin. During the entire follow-up $(42.6 \pm 30.5$ months), we recorded 5 $(0.02 \%)$ cases of primary TB infection in patients on anti-TNF $\alpha$ agents treatment, which had baseline screening negative for LTBI. Data and outcome of these patients are reported in Table 2. The mean time of follow-up of patients on bDMARDs treatment with positive QTF at baseline was $52.7 \pm 35.2$ months. bDMARD treatment regimens are reported in Table 3. No case of TB reactivation was found among patients with positive baseline QTF. Moreover, of 1563 (51.5\%) patients who repeated QTF during follow-up, $62(4 \%)$ of them showed a change in the test result. We observed a change to a positive state in 36 patients with previous negative QTF test, whereas 26 patients with previous positive QTF showed a shift to a negative test during follow-up.

Conclusion: Our study shows a prevalence of LTBI of $10.7 \%$ in Apulian patients affected with rheumatic disease. bDMARDs therapy appears to be safe in patients with positive QTF test treated according to current recommendations ${ }^{1}$. However, cases of primary TB infections, especially in patients receiving antiTNF $\alpha$ drugs, have been observed.

REFERENCES:

[1] Cantini F, et al, Guidance for the management of patients with latent tuberculosis infection requiring biologic therapy in rheumatology and dermatology clinical practice, Autoimmun Rev (2015).

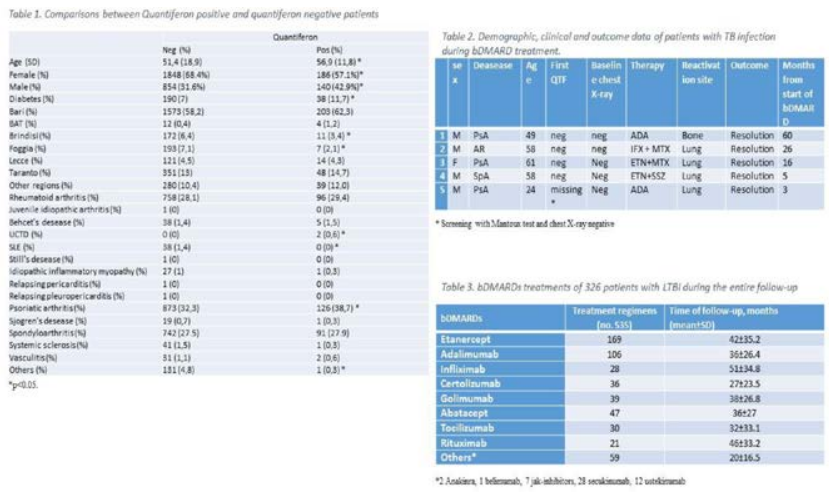

Disclosure of Interests: None declared

DOI: 10.1136/annrheumdis-2021-eular.2932

\section{POS1438 EARLY FACTORS ASSOCIATED WITH THE INITIATION OF TREATMENT WITH BIOLOGICS IN PATIENTS WITH AXIAL SPONDYLOARTHRITIS - RESULTS FROM A SINGLE CENTRE RETROSPECTIVE COHORT STUDY}

E. Costa ${ }^{1,2}$, L. Lages ${ }^{3}$, D. Esperança Almeida ${ }^{1,2}$, A. M. Gomes Correia ${ }^{1}$, M. Cerqueira ${ }^{1}$, J. Silva ${ }^{1}$, A. R. Ribeiro ${ }^{1}$, J. Redondo Costa ${ }^{1}$, J. Neves ${ }^{1} .{ }^{1}$ Hospital de Braga, Rheumatology, Braga, Portugal; ${ }^{2}$ Unidade Local de Saúde do Alto Minho, Rheumatology, Ponte de Lima, Portugal; ${ }^{3}$ University of Minho, School of Medicine, Braga, Portugal

Background: Axial Spondyloarthritis (axSpA) refers to a group of rheumatic dis eases that mainly affect the axial skeleton. Treatment with Biological Disease Modifying Anti-Rheumatic Drug (bDMARDs) is indicated when low disease activity is not achieved with Non-Steroid Anti-inflammatory Drugs. Some studies reported that some clinical and socio-demographic were associated with biologics initiation ${ }^{1,2}$. However, early factors associated with the initiation of bDMARDs have not been extensively studied.

The authors speculate that certain features early in disease presentation may be associated with future need for treatment with bDMARDs in patients with axSpA. Objectives: To study a population of patients with axSpA and determine whether the presence of certain factors at diagnosis is associated with a later need for biological treatment.

Methods: A single centre retrospective study was conducted comprising patients fulfilling the ASAS criteria for axSpA that attended the Rheumatology Outpatient Clinic from January to December 2019. Patients with psoriatic arthritis and enteropathic spondyloarthritis were excluded. All data, except regarding use of bDMARD, refers to the two initial appointments. Between group comparisons were performed through independent sample t-test or Chi-Square as applicable. Logistic Multivariate Regression was performed to understand which factors independently contributed to the use of bDMARDs.

Results: One hundred and fifty patients were included, and 52 patients $(34,7 \%)$ were under biological treatment. In comparison to the group that was not under treatment with bDMARDs, these were significantly more likely to be hard-workers $(57,8 \%$ vs $29,7 \% ; p=, 003)$, to have had elevated C-Reactive Protein $(81,6 \%$ vs $48,9 \%$; $p<, 001)$, to have had a grade of sacroiliitis greater than $2(67,4 \%$ vs $29,5 \% ; p<, 001)$ and to have history of enthesitis, $(32,7 \%$ vs $13,3 \% ; p=, 006)$. No differences between groups were found in sex, age, HLA-B27 positivity, state of employment, diagnostic delay, smoking status, history of dactylitis and history of uveitis. In multivariate regression analysis, only the hard-worker type and the highest grade of sacroiliitis were found to be independently associated with the use of bDMARDs as presented in Table 1. Although not statistically significant, a trend to association was found between elevated CRP at diagnosis and use of bDMARDs. 
Table 1. Multivariate logistic regression of variables associated with initiation of bDMARDs.

\begin{tabular}{|c|c|c|c|c|c|c|c|}
\hline & & $B$ & S.E. & Wald & OR & $95 \% \mathrm{Cl}$ & $p$ \\
\hline \multirow[t]{2}{*}{ Worker type ${ }^{a}$} & Non-hard & & & & ref. & & \\
\hline & Hard & 1,127 &, 509 & 4,890 & 3.09 & $1.14-8.37$ & $.027^{\star}$ \\
\hline \multirow[t]{2}{*}{ HLA-B27 } & Negative & & & & ref. & & \\
\hline & Positive & 1,153 & ,670 & 2,962 & 3.17 & $0.85-11.77$ & .085 \\
\hline \multirow[t]{2}{*}{$\mathrm{CRP}^{a}$} & Normal & & & & ref. & & \\
\hline & $\begin{array}{c}\text { Elevated } \\
\leq 2\end{array}$ & 1,003 &, 529 & 3,591 & $\begin{array}{l}2.73 \\
\text { ref. }\end{array}$ & $0.97-7.69$ & .058 \\
\hline Grade of Sacroiliitis $^{a}$ & $>2$ & 1,485 & ,489 & 9,226 & 4.41 & $1.69-11.50$ & $.002^{*}$ \\
\hline History of Enthesitis ${ }^{a}$ & Yes & ,299 &, 574 & ,272 & 1.35 & $0.44-4.15$ & .602 \\
\hline
\end{tabular}

${ }^{a}$ At the time of diagnosis; ref. - referenceS.E. - Standard Error; OR - Odds Ratio; $\mathrm{Cl}$ Confidence Interval

Conclusion: In our study, the performance of work associated with greater biomechanical stress and the presence of greater structural damage at diagnosis were shown to be associated with the latter use of bDMARDs. The authors highlight the importance of recognizing these factors that seem to relate to more aggressive disease, with more structural damage, thus suggesting a need for a tighter control management strategy in these patients accordingly current guidelines. More studies still needed to better depict the influence of certain early clinical and patient related variables in management of axSpA patients.

REFERENCES:

[1] Png WY, Kwan YH, Lee YX, et al. Factors Associated with Initiation of Biologics in Patients With Axial Spondyloarthritis in an Urban Asian City: A PRESPOND Study. J Clin Rheumatol. 2019 Mar;25(2):59-64.

[2] Inman R, Garrido-Cumbrera M, Chan J, et al SAT0629-HPR FACTORS ASSOCIATED WITH USE OF BIOLOGICAL THERAPIES FOR AXIAL SPONDYLOARTHRITIS IN CANADA. RESULTS FROM THE IMAS SURVEY. Annals of the Rheumatic Diseases 2020;79:1274-1275.

Disclosure of Interests: None declared

DOI: 10.1136/annrheumdis-2021-eular.2952

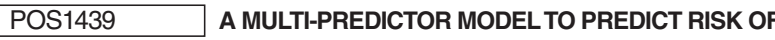 SCLERODERMA RENAL CRISIS IN SYSTEMIC SCLEROSIS}

D. $\mathrm{Xu}^{1}$, R. Mu ${ }^{1} .{ }^{1}$ Peking University Third Hopsital, Department of Rheumatology and Immunology, Beijing, China

Background: Scleroderma renal crisis (SRC) is a life-threatening syndrome. The early identification of patients at risk is essential for timely treatment to improve the outcome $e^{[1]}$

Objectives: We aimed to provide a personalized tool to predict risk of SRC in systemic sclerosis (SSc).

Methods: We tried to set up a SRC prediction model based on the PKUPH-SSc cohort of 302 SSc patients. The least absolute shrinkage and selection operator (Lasso) regression was used to optimize disease features. Multivariable logistic regression analysis was applied to build a SRC prediction model incorporating the features of SSc selected in the Lasso regression. Then, a multi-predictor nomogram combining clinical characteristics was constructed and evaluated by discrimination and calibration.

Results: A multi-predictor nomogram for evaluating the risk of SRC was successfully developed. In the nomogram, four easily available predictors were contained including disease duration $<2$ years, cardiac involvement, anemia and corticosteroid $>15 \mathrm{mg} / \mathrm{d}$ exposure. The nomogram displayed good discrimination with an area under the curve (AUC) of $0.843(95 \% \mathrm{Cl}: 0.797-0.882)$ and good calibration. Conclusion: The multi-predictor nomogram for SRC could be reliably and conveniently used to predict the individual risk of SRC in SSc patients, and be a step towards more personalized medicine.

REFERENCES:

[1]Woodworth TG, Suliman YA, Li W, Furst DE, Clements P (2016) Scleroderma renal

crisis and renal involvement in systemic sclerosis. Nat Rev Nephrol 12 (11):678-91. Disclosure of Interests: None declared

DOI: 10.1136/annrheumdis-2021-eular.3613

\section{POS1440 ASSOCIATION BETWEEN SERUM URATE AND INFLAMMATORY MARKERS IN YOUNG ADULTS: CROSS SECTIONAL FINDINGS FROM A BIRTH COHORT}

T. Loyola Correa ${ }^{1}$, I. Oliveira de Oliveira ${ }^{2} .{ }^{1}$ Universidade Federal de Pelotas, Faculty of Medicine, Pelotas, Brazil; ${ }^{2}$ Universidade Federal de Pelotas, Postgraduate Program in Epidemiology, Pelotas, Brazil
Background: Uric acid is the end product of purine metabolism and an abruptly increase or decrease on its serum concentrations can form free urate crystals and precipitate a gout attack. Serum urate (SU) has been positively and independently associated with cardiometabolic diseases in observational studies, but causal roles remain unclear. $^{1}$ In addition inflammatory markers are deeply associated with cardiometabolic diseases, such as essential hypertension and type 2 diabetes mellitus. ${ }^{2}$ How ever, little has been published about the association of SU and subclinical inflammation.

Objectives: To assess the associations of SU with interleukin 6 (IL-6), C-reactive protein (CRP), and adiponectin at 22-year-old individuals belonging to the 1993 birth cohort of Pelotas (Brazil).

Methods: During 1993, all live born babies in the city were invited to take part in a prospective study and sub-samples of this cohort were followed-up since then. At the 22-year follow-up, interviews and clinical measurements were performed and non-fasting blood samples were drawn from the participants SU was evaluated by enzymatic-colorimetric assay; IL- 6 and adiponectin, by immunoassay; and CRP by immunoturbidimetric assay. The co-variables taken into consideration were skin color; asset index at 22 years; cardiometabolic risk factors (body mass index, systolic and diastolic blood pressure); presence of cardiometabolic diseases (hypertension, diabetes and dyslipidemia); and behavioral variables (alcohol use disorder, smoking status and physical inactivity). Exposition variables were categorized into tertiles. Sex-stratified linea regressions have been performed using STATA 13 and $p<0.05$ was considered statistically significant.

Results: The sample was composed by 1657 (46.3\%) men and 1921 (53.7\%) women of 22 years old. The median (25-75 IQR) for IL-6 (pg/mL) was highe in women than in men $[1.26(0.85 ; 2.02)$ vs. $1.07(0.76 ; 1.69)]$; the same was observed for CRP $(\mathrm{mg} / \mathrm{dL})[1.6(0.6 ; 4.1)$ vs. $0.6(0.3 ; 1.4)]$. The mean $(95 \% \mathrm{Cl})$ for adiponectin $(\mu \mathrm{g} / \mathrm{mL})$ was also higher in women $[10.72(10.50$ $10.94)$ vs. $7.97(7.78 ; 8.16)]$. As expected, the mean $( \pm S D)$ for $S U(m g / d L)$ was higher in men $(5.2 \pm 1.2$ vs. $3.9 \pm 1.1)$. In adjusted analysis, IL-6 was positively associated with SU only in women; $p=0.018$ (Table 1). CRP was positively associated with SU in crude and adjusted analyses for both sexes; $p=0.002$ (Table 1). In addition, higher adiponectin was independently associated with lower concentrations of SU for men $(p<0.001)$ and women $(p=0.013)$ (Table 1).

Conclusion: The increase of SU is associated with IL-6 and CRP increasing and adiponectin decreasing since early adult age.

REFERENCES:

[1] Mortada I. Curr Hypertens Rep. 2017;19(9):69.

[2] Pouvreau C et al. J Inflamm Res. 2018;19(11):61-68.

Table 1. Mean SU concentrations ( $\mathrm{mg} / \mathrm{dL}$ ) according to physiological markers' tertiles

\begin{tabular}{|c|c|c|c|c|c|c|c|c|c|}
\hline \multirow{3}{*}{$\begin{array}{l}\text { Physiological } \\
\text { marker }\end{array}$} & \multirow[b]{3}{*}{ Tertile } & \multicolumn{4}{|c|}{ Men } & \multicolumn{4}{|c|}{ Women } \\
\hline & & \multicolumn{2}{|c|}{ Crude } & \multicolumn{2}{|c|}{ Adjusted } & \multicolumn{2}{|c|}{ Crude } & \multicolumn{2}{|c|}{ Adjusted } \\
\hline & & Mean & $\mathrm{Cl} 95 \%$ & Mean & $\mathrm{Cl} 95 \%$ & Mean & $\mathrm{Cl} 195 \%$ & Mean & Cl95\% \\
\hline & & & $p<0.001$ & & $p=0.12$ & & $p<0.001$ & & $p=0.018$ \\
\hline \multirow[t]{4}{*}{ IL-6 } & 1 & 5.01 & $\begin{array}{l}(4.91 \\
5.12)\end{array}$ & 5.16 & $\begin{array}{l}(5.06 \\
5.26)\end{array}$ & 3.67 & $\begin{array}{l}(3.58 \\
3.77)\end{array}$ & 3.85 & $\begin{array}{l}(3.76 ; \\
3.95)\end{array}$ \\
\hline & 2 & 5.29 & $\begin{array}{l}(5.19 \\
5.40)\end{array}$ & 5.30 & $\begin{array}{l}(5.19 \\
5.40)\end{array}$ & 3.81 & $\begin{array}{l}(3.72 \\
3.90)\end{array}$ & 3.88 & $\begin{array}{l}(3.79 \\
3.97)\end{array}$ \\
\hline & 3 & 5.46 & $\begin{array}{l}\text { (5.35; } \\
5.58)\end{array}$ & 5.30 & $\begin{array}{l}(5.18 \\
5.42)\end{array}$ & 4.23 & $\begin{array}{l}(4.14 ; \\
4.31)\end{array}$ & 4.03 & $\begin{array}{l}\text { (3.94; } \\
4.12)\end{array}$ \\
\hline & & & $p<0.001$ & & $p=0.002$ & & $p<0.001$ & & $p=0.002$ \\
\hline \multirow[t]{4}{*}{ CRP } & 1 & 5.01 & $\begin{array}{l}(4.93 \\
5.09)\end{array}$ & 5.14 & $\begin{array}{l}(5.05 \\
5.22)\end{array}$ & 3.57 & $\begin{array}{l}(3.47 \\
3.66)\end{array}$ & 3.77 & $\begin{array}{l}(3.67 \\
3.87)\end{array}$ \\
\hline & 2 & 5.37 & $\begin{array}{l}(5.26 \\
5.47)\end{array}$ & 5.31 & $\begin{array}{l}(5.20 \\
5.41)\end{array}$ & 3.89 & $\begin{array}{l}(3.80 \\
3.98)\end{array}$ & 3.95 & $\begin{array}{l}(3.86 \\
4.03)\end{array}$ \\
\hline & 3 & 5.62 & $\begin{array}{l}(5.48 \\
5.75)\end{array}$ & 5.42 & $\begin{array}{l}(5.28 \\
5.56)\end{array}$ & 4.13 & $\begin{array}{l}(4.06 \\
4.20)\end{array}$ & 3.99 & $\begin{array}{l}(3.92 \\
4.06)\end{array}$ \\
\hline & & & $p<0.001$ & & $p<0.001$ & & $p<0.001$ & & $p=0.013$ \\
\hline \multirow[t]{3}{*}{ Adiponectin } & 1 & 5.45 & $\begin{array}{l}(5.37 \\
5.54)\end{array}$ & 5.36 & $\begin{array}{l}(5.27 \\
5.45)\end{array}$ & 4.26 & $\begin{array}{l}(4.16 \\
4.36)\end{array}$ & 4.06 & $\begin{array}{l}(3.95 \\
4.16)\end{array}$ \\
\hline & 2 & 5.09 & $\begin{array}{l}(4.99 \\
5.20)\end{array}$ & 5.19 & $\begin{array}{l}(5.09 \\
5.30)\end{array}$ & 3.93 & $\begin{array}{l}(3.84 \\
4.01)\end{array}$ & 3.91 & $\begin{array}{l}(3.83 ; \\
3.99)\end{array}$ \\
\hline & 3 & 4.97 & $\begin{array}{l}(4.84 \\
5.09)\end{array}$ & 5.07 & $\begin{array}{l}(4.94 \\
5.19)\end{array}$ & 3.75 & $\begin{array}{l}(3.67 ; \\
3.82)\end{array}$ & 3.86 & $\begin{array}{l}(3.79 ; \\
3.93)\end{array}$ \\
\hline
\end{tabular}

Disclosure of Interests: None declared

DOI: 10.1136/annrheumdis-2021-eular.3790 